\title{
Identifying Criteria of Weariness on Urban Areas (Case Study: Samen District of Mashhad)
}

\author{
Javad Babaei $^{1^{*}}$, Mohammad Rahim Rahnama ${ }^{2}$, Bara'at Ali Khakpour ${ }^{3}$ and Mohammad Shokouhi ${ }^{4}$ \\ ${ }^{I}$ PhD student in Geography and Urban Planning, International Branch of Ferdowsi University of Mashhad, Mashhad, Iran \\ ${ }^{2}$ Professor of Geography and Urban Planning, Ferdowsi University of Mashhad, Mashhad, Iran, corresponding author \\ ${ }^{3}$ Associate Professor of Geography and Urban Planning, Ferdowsi University of Mashhad, Mashhad, Iran \\ ${ }^{4}$ Associate Professor of Geography and Urban Planning, Ferdowsi University of Mashhad, Mashhad, Iran \\ *Corresponding author E-mail: Javad.babaei47@gmail.com
}

\begin{abstract}
Today, one of the challenges of modern urbanization in Iran is the issue of old and worn-out urban textures and identification of their criteria. Samen District of Mashhad, a historical texture in an area of 321 hectares, was selected as the study sample. The aim of this study was to determine priorities of improving old neighborhoods based on criteria of weariness. The research adopted a descriptive-analytical method and used the model of Analytical Hierarchy Process (AHP) for the process analysis. The data collection was conducted by a questionnaire (according to Cochran's formula, 287 questionnaires were randomly distributed in 6 neighborhoods using random sampling method), mapping and field study. Six parameters and twenty four indices were measured as criteria affecting the weariness process. Results showed that physical, constructional, environmental, economic, and social and services parameters had respectively the highest impact on worn-out urban texture. In addition, Eidgah, Payin Khiyaban, Tabarsi, Noghan, Bala Khiyaban and Chaharbagh were ranked first and sixth in terms of the degree of weariness and intervention priorities were specified in each neighborhood.
\end{abstract}

Keywords: worn-out texture, weariness criteria, restoration, Mashhad.

\section{Introduction}

\subsection{Statement of the Problem}

One of the problems that cities across the country face is related to the incompatibility between the needs of modern citizens and old texture, which has given rise to a plethora of problems, especially in terms of physical form. A large portion of urban fabrics have turned into worn out textures, thereby contributing to the declining quality of life in urban areas and their abandonment by local residents. As a global phenomenon in cities around the world, this issue may only vary in terms of external manifestations, which is provoked by the type and nature of intervention adopted to deal with the issue of worn out urban textures by municipal planning authorities.

Worn-out fabrics are considered as valuable resources in urban areas and only guardians of old fabrics can protect and maintain this valuable heritage. Therefore, in an attempt to improve and resolve the problems of these neighborhoods through various interventions, it is necessary to adopt accurate and exhaustive criteria for the identification of these fabrics, and proportional to the nature and extent of weariness, recommend appropriate strategy to tackle this problem. According to estimates of state officials and the Department of Housing and Urban Development, there are 87 thousand hectares of old urban fabric in more than 100 cities of Iran, with 37,000 hectares of this worn-out fabric being located in cities of over 200,000 people and 50 thousand hectares in cities of above 100,000 people[1]. As the second metropolis of Iran, Mashhad is among cities with the largest portion of worn-out textures and unofficial settlements across the country with a total of 2292 hectares of old fabrics scattered around urban areas and about 4000 hectares of unofficial settlements The ratio of worn-out textures in Mashhad to total worn-out fabric at national level is $3 \%$ and it is regarded as the third largest city of Iran in terms of worn-out fabrics after Tehran and Tabriz. In this context, the estimated area of worn-out textures in Tehran, Tabriz and Mashhad is 326,2522 and 2292 hectares respectively with a population of 519,852 people living in the old texture of Mashhad [2].

Moreover, great capacities and potentials of Mashhad, which have led to the selection of this city as the spiritual capital of the Islamic world, and distinguish it as one of the major cities in Iran and the world, highlight the importance of further attention to urban areas, especially the old and worn-out textures of this city.

Samen District, as part of the historical fabric of Mashhad, serves as the urban identity of this city, though approximately 321 hectares of this district is composed of worn out textures. Given that a large portion of worn-out urban fabrics are concentrated in historical and old fabric of the city, it is of utmost importance to focus on resolving the issues of these areas [3].

What is now regarded as the standard practice for the relevant agencies in relation to the identification of worn out tissues is limited to three physical parameters, namely instability, impermeability and 
small density criteria. However, apparently, these parameters cannot be applied to all cities and even districts of a city as identifying factors and solutions for improvement and organization of such derelict fabrics. That is, cities and neighborhoods relative to their unique features and characteristics require consideration and adoption of a distinctive approach to intervention and organization of their old fabrics, as each parameter has a distinct share in weariness of diverse urban areas.

The adoption of a holistic approach that include all physical, economic, social, environmental, constructional and services aspects can help improve the quality of human environment and create added social and economic values in cities. In the same line of research, this paper intends to explore these textures with emphasis on criteria of their identification, for it seems that mere reliance on three physical parameters is not sufficient to label all districts and neighborhood as derelict, and there is not a panacea for tackling the problems of these old textures.

The aim of this study is to specify priorities of organizing and improving worn-out neighborhoods in Samen District of Mashhad through determining criteria of identifying weariness. To achieve this goal, the following hypotheses were presented:

- It appears that besides three physical parameters presented by the Iranian Supreme Council for Planning and Architecture, economic, social, constructional and services criteria can also contribute to the weariness of neighborhoods.

- There seems to be a relationship between scale, intensity and nature of weariness in worn-out neighborhoods.

\subsubsection{Worn-Out Texture and its Features}

Worn-out urban textures refer to areas within cities which due to physical weariness and lack of proper roadway access, facilities, services and infrastructure are vulnerable and possess negligible environmental, economic and (implicitly) social values. Given the poverty of residents and their owners, it is not feasible to renovate these textures and investors lack necessary incentives to invest in those zones [4]. The various types of worn-out textures can be divided into seven categories: with/without cultural heritage, historically valuable, inefficient, disorganized and problematic, marginal, and rural areas located in urban zone. According to this classification, contrary to the general expectation, worn-out texture should be differentiated from old textures as the former can encompass marginal and rural areas in the outskirt of cities as well.

Therefore, it is erroneous to apply the term worn-out textures merely to old and historical urban areas.

With the passage of time and absence of necessary investment for their maintenance, worn-out textures encounter certain problems including: difficulty of access to the inner areas of the texture, absence of proper infrastructure, environmental problems, intense pollution, lack of facilities designed for leisure time, poverty and deprivation, vulnerability to earthquakes, low per capita services, large population (high population density), unsustainable building density, insecurity and social problems [5]. Iranian Supreme Council for Planning and Architecture has described the features of worn-out urban textures in form of six criteria as follows:

Structure life (mainly old buildings without technical standards which are vulnerable to earthquake of moderate intensity);

Small density and number of floors (buildings with an area of less than 200 square meters, mostly 1 to 2 floors);

Type of materials (mostly made of adobe, adobe and brick, wood or brick and iron without obeying standard procedures related to horizontal and vertical joints);

Accessibility (mainly consisting of irregular structures, which can only be accessed by foot with passageways less than 6 meters in width and a permeability rate of less than $30 \%$ );

Services and urban infrastructure (suffering from serious shortage of services, infrastructure and open, green and public spaces);

Qualitative criteria (population density of textures, protected areas around faults, course of Qanats, rivers and valleys and rural areas within cities, etc.) $[6,7]$

\subsubsection{Determining the Range of Worn-Out Urban Textures based On Different Types of Weariness Parameters}

In the literature, a number of criteria and parameters have been proposed to identify derelict urban textures. Table 1 describes some of these parameters:

Table 1: Criteria of weariness (results derived from previous studies)

\begin{tabular}{|c|c|c|}
\hline Researcher / year & Title of work & Applied parameters and criteria \\
\hline Rahnama et al. (2008) & $\begin{array}{l}\text { Integrative application of Analytical Hierarchy Process } \\
\text { Model and GIS to identify the priorities of development } \\
\text { in urban centers: (case study of Pachenar neighborhood } \\
\text { of Mashhad) }\end{array}$ & $\begin{array}{l}\text { size of properties / degree of weariness /passageways width / } \\
\text { usage / durability of buildings }\end{array}$ \\
\hline Hasani (2008) & $\begin{array}{l}\text { "Evaluation and measurement of worn-out urban tex- } \\
\text { ture using fuzzy logic and Index Overlay in the GIS }\end{array}$ & $\begin{array}{l}\text { Structure life /type of materials/ number of floors / access to } \\
\text { the network of roads / access to infrastructure services } \\
\text { /positioning in the range of natural and synthetic factors / own- } \\
\text { ership / property price }\end{array}$ \\
\hline $\begin{array}{l}\text { Aliakbari and Emad al-Din } \\
(2008)\end{array}$ & $\begin{array}{l}\text { Structural-functional empowerment of worn-out urban } \\
\text { textures }\end{array}$ & $\begin{array}{l}\text { Physical -spatial /social -demographic /functional system / } \\
\text { motor system / urban economy / infrastructure / environmental } \\
\text { / urban management }\end{array}$ \\
\hline $\begin{array}{l}\text { Farnahad Consulting Engineers } \\
\text { (2009) }\end{array}$ & Development plan of Mashhad Metropolis & $\begin{array}{l}\text { physical / functional / socioeconomic / environmental / infra- } \\
\text { structural / legal / managerial }\end{array}$ \\
\hline Pourjafar (2009) & $\begin{array}{l}\text { Principles of modernization and rehabilitation of old } \\
\text { urban textures }\end{array}$ & physical / social / economic / environmental \\
\hline Majedi (2010) & Modern urban developments, future worn-out texture & $\begin{array}{l}\text { functional / physical / communication network / environmental } \\
\text { / economic / infrastructure / legal / managerial }\end{array}$ \\
\hline Azizi (2010) & $\begin{array}{c}\text { Designing and defining criteria for identifying worn-out } \\
\text { urban textures (Case study: Shiraz) }\end{array}$ & $\begin{array}{c}\text { A set of social, economic, demographic and environmental } \\
\text { criteria, both qualitative and quantitative, in combination with } \\
\text { physical criteria }\end{array}$ \\
\hline $\begin{array}{l}\text { Zangiabad, Khosravi and } \\
\text { Sahraeian (2011) }\end{array}$ & $\begin{array}{l}\text { Determining criterial for identification of worn-out } \\
\text { urban texture using GIS (Case study: western boundary }\end{array}$ & $\begin{array}{l}\text { physical factors (small density / permeability / quality of build- } \\
\text { ings / structure of buildings / structure life) }\end{array}$ \\
\hline
\end{tabular}




\begin{tabular}{|l|c|c|}
\hline & of worn-out fabric in the city Jahrom" & \\
\hline Alipur et al. / 201 & $\begin{array}{c}\text { The role of environmental quality criteria in identifying } \\
\text { priorities for intervention in worn-out textures within } \\
\text { the city of Bandar Lengeh }\end{array}$ & $\begin{array}{c}\text { impermeability / small density / instability / environmental } \\
\text { resolutions }\end{array}$ \\
\hline
\end{tabular}

The results of these research projects suggest that the three criteria proposed by the Supreme Council for Urban Planning and Architecture are not sufficient to identify worn-out textures.

\subsection{Activities Related to Urban Restoration}

Restoration refers to maintenance and preservation of existing textures with the minimum cost and least degradation and at the same time attempting to eliminate shortcomings and deficiencies [8].

As a continuous process, restoration is not limited to a specific time period and it should not be considered as a temporal solution. Restoration is carried out in two ways: repair and maintenance. Repair refers to a set of interventions aimed at improving the physical condition of urban space. Maintenance, however, adopts a standpoint broader than that of repair, focusing on the modernity of a texture, encompassing a range of interventions intended to enhance urban space (activity-physical form) and its modernization.

Based on this definition, urban restoration is used to mean [9].

In the field of urbanization and urban planning, a variety of strategies and interventions have been presented for the improvement of urban centers or more accurately, old and usually worn-out textures. Different types of intervention, based on the degree of loyalty to the past, can be divided into three groups of betterment, renovation and reconstruction [10].

A variety of definitions for urban restoration measures have been proposed by experts. In the following section, some of these definitions are briefly discussed.

Betterment: It can refer to both actions adopted to improve the current situation of the city and creation of a situation that include a number of measures aimed at promoting the status quo.

Therefore, betterment can be used in the sense of improvement, enhancement and promotion of the subject or work under study.

Here, the main point is the range of action and quantities that are employed to foster quality.

[11]. Betterment is intended to maintain and improve the physical and spatial forms of cities over a short period of time [12].In this type of intervention, the emphasis is on loyalty to the past and preservation of their identifying features. Betterment activities are undertaken to tap into existing potential and actual facilities and reinforcing positive aspects and weakening negative aspects through support, preservation, protection, revival, stabilization and repair [13].

Renovation: it refers to a series of measures adopted to prepare grounds in physical and spatial structures through establishing a compromise between old texture and space and the needs of modern society [14]. Innovation encompasses the spectrum of actions that not only preserve a building, but also modernize the old urban space or spatial structure and prepares the ground for its optimum productivity.

Renovation is possible when the available space functions effectively and properly but the relative weariness of the "physical form" has deteriorated its efficiency and productivity [4]. Renovation practices are aimed at promoting efficiency and restoring the urban life to worn-out tissues [15].

Reconstruction (or Gentrification): it indicates the re-development or revamping of a texture when the intensity of weariness and inactiveness is remarkable and directs investment and intervention of executive bodies are required. In this case, policies and reactions undertaken to fight such weariness with the purpose of restoring balance to these textures are known as re-development [1]. Recon- struction means rebuilding, which is implemented when an urban space or complex is overwhelmed by weariness and decrepitude [14].

\section{Material and Method}

\subsection{Method}

This is an applied developmental study with a descriptive-analytical approach. The data collection, including theoretical and field data, was conducted using a variety of resources including books, papers, institutional data, questionnaires, maps and images. The sample size, considering the study population and the number of households residing in the area was calculated by Cochran's formula and after incorporating the moderating factors of the study, 287 questionnaires were prepared and distributed in neighborhoods under study.

The simple probability sampling method was adopted. To evaluate the validity and reliability of the questionnaire, a sample of 30 questionnaires was distributed at neighborhoods and a Cronbach's alpha coefficient of 0.811 was achieved.

The criteria under study were compared and contrasted with respect to six parameters (physical, environmental, social, economic, structural and services) and 24 indices using Analytic Hierarchy Process. Moreover, worn-out neighborhoods were also compared and ranked in terms of these criteria and indicators.

This process allowed the ranking of different alternatives of the problem based on extracted priorities and finally intervention priorities in the context of neighborhood were determined in accordance with the type and degree of weariness and decrepitude.

In this research, this model was designed by Expert Choice software.

\subsection{Research Variables and Indicators}

The criteria and indices proposed for the worn-out textures, which were extracted from the analysis of literature on weariness criteria, are as follows:

1. Physical: impermeability, mass to space ratio, flooring and inappropriate materials of passages;

2. Economic: low cost housing, low-income households and unemployment;

3. Environmental: annoying usages, lack of green space, unsanitary conditions (garbage and sewage), substandard buildings, debris and demolition wastes;

4- Services: bare land, ruins and abandoned buildings, absence of diversity in land usages across the neighborhood level, lack of adequate service coverage and limited standard land usage area at the neighborhood scale;

5. Social: insecurity, large family size, intense population density, ethnic diversity, high density of households inhabiting in residential units, negative growth rate, non-indigenous residents, high rate of illiteracy;

6. Constructional: small density, old-designed building and instability

\section{Geographical Scope of the Research}

According to municipality divisions, Mashhad is comprised of 13 districts. As noted in 2015 Statistical Yearbook of Mashhad, Samen area with a population of 16549 people is located in the center of the 
city. It is contiguous to districts $1,2,3,4,5,6,7$ and 8 . In an area of 321 hectares, this district consists of four regions and six neighborhoods (including Chaharbagh, Bala Khiyaban, Noghan, Payin Khiyaban, Tabarsi and Eidgah) which are considered as worn-out textures and cover a total area of 321 hectares with 16549 inhabitants. The worn-out texture of Mashhad and Samen district are respectively 23019 and 321 hectares respectively. It should be noted that the worn-out neighborhoods were determined based on three criteria (small-density, instability and impermeability) adopted by Iranian High Council for Urban Planning and Architecture in June 6, 2005, Among thirteen districts of Mashhad, District 6 with four blocks in an area of 420.166 hectares is ranked first in terms of the vastness of worn-out texture. Map 1 shows the location of the area under study.

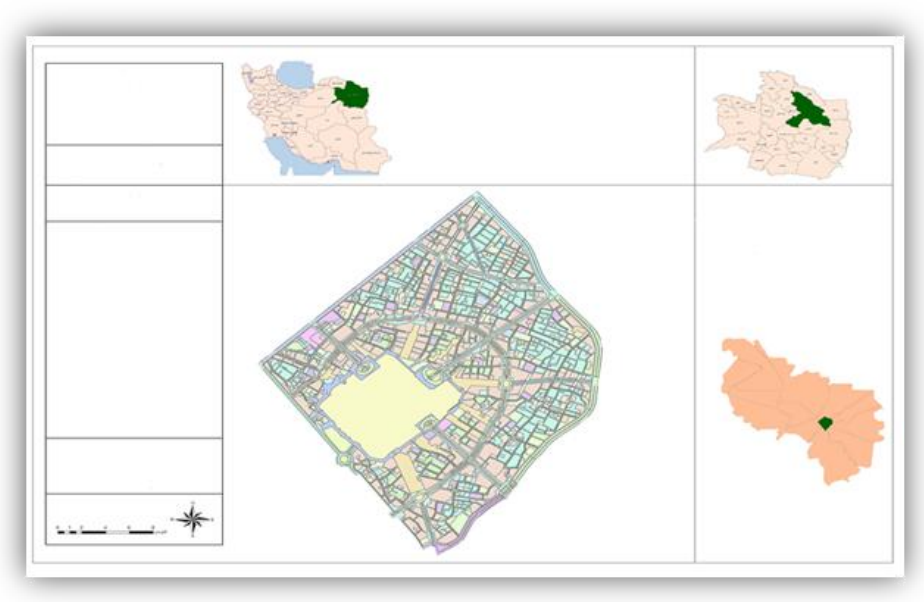

Map 1: Location of the area under study

\section{Results}

\subsection{Prioritization of Criteria and Sub-Criteria of Weari- ness}

The data analysis was performed using AHP model. This method allows ranking different alternatives of a problem based on extracted priorities [16]. This process involved several weighting and scoring steps, which are described in the following section.
The first weighting step was associated with six primary physical, economic, social, environmental, constructional and services criteria. The numerical results are shown in Table 2.

The inconsistency factor at this stage was smaller than 0.1 (incompatibility factor $=0.02$ ). Thus, any compatibility in judgments was acceptable. In Tables 2 and 3, the criterion with utmost importance has been shown in the first rank.

Table 2: Scoring and ranking of 6 main criteria based on paired comparisons

\begin{tabular}{|c|c|c|c|c|c|c|}
\hline Criteria & Physical & Economic & Social & Environmental & Service & Constructional \\
\hline Score & 0.367 & 0.083 & 0.078 & 0.193 & 0.048 & 0.318 \\
\hline Rank & 1 & 4 & 5 & 3 & 6 & 2 \\
\hline
\end{tabular}

In the next step of this process, a paired comparison of sub-criteria was conducted, as shown in Table 3 . Since the inconsistency coeffi- cient at this step was smaller than 0.1 , the compatibility of judgments was accepted

Table 3: Scoring and ranking of 24 sub-criteria (indices) based on paired comparisons

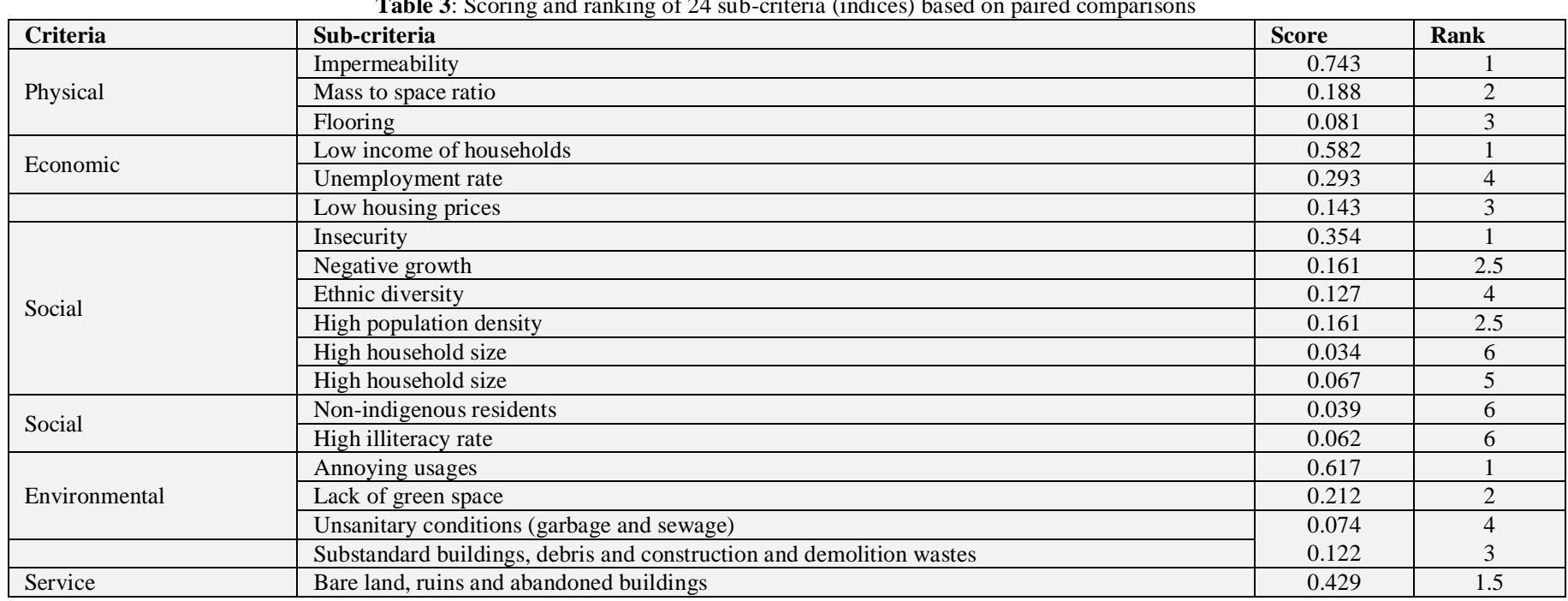




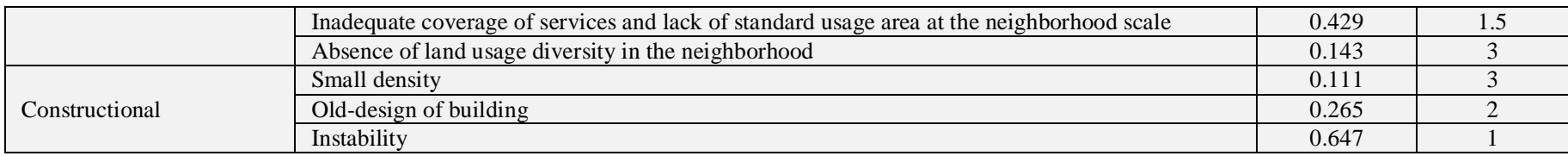

\subsection{Prioritization of Neighborhoods in Terms of Criteria and Sub-Criteria of Weariness}

In the next step, six neighborhoods selected in the Samen District (Chaharbagh, Bala Khiyaban, Noghan, Payin Khiyaban, Tabarsi and Eidgah) were subject to paired comparisons with respect to each sub-criteria. This comparison was based upon the study of each criterion in intended neighborhoods and the respective ranking of the neighborhood was determined based on indicators related to each criterion and sub-criterion.

Table 4 shows the ranking of neighborhoods based on the main criteria. For instance, it can be observed that Eidgah neighborhood was ranked first to third in terms of each criterion but the ranking of Chaharbagh neighborhood in all criteria was between fifth and sixth In general, therefore, with respect to the weariness criteria, Eidgah and Chaharbagh neighborhoods were ranked first and sixth respectively.

Table 4: Ranking of each neighborhood in terms of main criteria

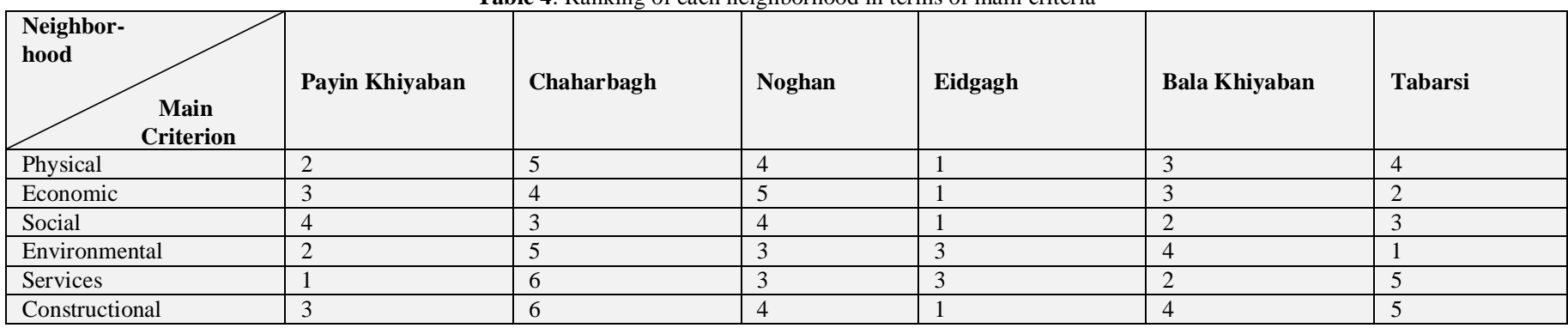

In the final weighting step of this process, the final score of each neighborhood was determined by applying coefficients of criteria and sub-criteria and the ranking of each neighborhood. Table 5 shows the final score and ranking of each neighborhood. The paired comparison of all six neighborhoods in terms of six criteria and 24 sub-criteria revealed that Eidgah and Chaharbagh neighborhoods were ranked first and sixth respectively. In fact, the highest and lowest degree of weariness belonged to Chaharbagh and Eidgah neighborhoods.

Table 5: Prioritization of neighborhoods in terms of scale of weariness

\begin{tabular}{|l|c|c|c|c|c|c|}
\hline Neighborhood & Payin Khiyaban & Eidgah & Bala Khiyaban & Tabarsi & Charbagh & Noghan \\
\hline Score & 0.293 & 0.743 & 0.076 & 0.143 & 0.069 & 0.127 \\
\hline Ranking & 2 & 1 & 5 & 3 & 6 & 4 \\
\hline
\end{tabular}

\section{Discussion}

\subsection{Determining the Method of Intervention based on the Type of Weariness}

As discussed earlier, the degree of weariness and type of urban space restoration depend on the type of space weariness. Therefore, by identifying the condition of neighborhood texture, the type and scale of weariness can be determined, and accordingly the proper intervention and restoration strategy can be proposed.

In this study, six criteria and 24 related sub-criteria were evaluated in 6 neighborhoods located in Samen District of Mashhad, and depending on the priority and ranking of each neighborhood with respect to these criteria, their current situation was determined. The results are presented in related Tables.

According to various definitions of weariness, it appears impractical to propose a conclusive method of intervention and an exclusive type of weariness for the texture of neighborhoods under study. The results suggest that each neighborhood requires a variety of intervention methods tailored to its deterioration condition in terms of related criteria and sub-criteria.

It can therefore be concluded that all neighborhoods suffer from relative weariness of texture practice and functions and in a sense the abandonment of residential and commercial units, which accounts for the bulk of its weariness.
In fact, these units are in need of betterment through modification, creation of new land usages and inclusion of different aspects of restoration. The only difference is that the priority of implementing these interventions in neighborhoods varies depending on the relative weariness (activity / function).

In addition, in all neighborhoods under study, there are blocks that are structurally unstable and suffer from severe physical quality deterioration, particularly historical monuments and buildings remained from past centuries. Thus, these blocks are characterized with relative physical weariness and in need of renovation, with special emphasis on the usage and change of physical form and different aspects of renovation. Similar to the betterment method, here the prioritization of neighborhoods based on the innovation rested upon the existence of these categories and their severity.

In contrast to the relative weariness discussed above, there is another kind of weariness related to both physical form and activity, which is known as total urban space weariness. The repair of these structural units is only possible through reconstruction, which means the reorganization of the entire unit through demolition, cleanup and rebuilding.

This method is commonly employed at urban scale or in part of the city. Therefore considering that the present study was performed at the neighborhood scale, and all neighborhoods under study were located in an urban district with relatively identical history of texture formation and development, attempted were made to avoid recon- 
struction method when weariness could be eliminated by betterment or renovation.

However, the study of neighborhoods demonstrated that some of them comprised of abandoned and dilapidated blocks, which were physically and functionally worn-out and thus in need of reconstruction.
It should be noted that the number and scale of these blocks at the level of neighborhood was limited, and they were especially concentrated in Eidgah neighborhood.

Table 6 shows score and ranking of neighborhoods (based on the results of AHP model) and the priority intervention in the neighborhood.

Table 6: Scores, ranking and first and second priorities of intervention in neighborhoods under study

\begin{tabular}{|c|c|c|c|c|c|c|}
\hline Neighborhood & Payin Khiaban & Eidgah & Bala Khiyaban & Tabarsi & Chaharbagh & Noghan \\
\hline Score & 0.293 & 0.743 & 0.076 & 0.143 & 0.069 & 0.127 \\
\hline Ranking & 2 & 1 & 5 & 3 & 6 & 4 \\
\hline & Betterment & Betterment & Betterment & Betterment & Betterment & Betterment \\
\hline & Betterment & Renovation & Renovation & Renovation & Betterment & Betterment \\
\hline
\end{tabular}

\section{Conclusions}

The results of this study suggested that a host of other criteria are involved in weariness of urban textures so that three physical criteria of small density, instability and impermeability in neighborhood texture are not sufficient to put the label of weariness on a neighborhood.

In fact, a range of different processes lead to decrepitude and inefficiency of these textures and just one or more physical factors cannot be held responsible for this issue.

Moreover, restoration measures require accurate identification of the area and selection of the most appropriate method of intervention tailored to the type of weariness.

It can be posited that these criteria also affect the identification of intervention priorities. Basically, these criteria only encompass certain physical properties, whereas other social, economic and environmental criteria due to their connection with human issues are also involved in weariness phenomenon. As such, absolute focus on physical criteria as the main indices of weariness lacks the efficacy required to determine and identify worn-out textures.

In short, the points discussed above highlight the necessity of reviewing current indices used to identify derelict urban texture so that with the development of more comprehensive criteria, the neighborhood textures can be evaluated from all aspects. It also allows making a distinction between weariness of neighborhood and diverse conditions and features, and then proposing the appropriate method of intervention depending on the type, intensity and scale of weariness.

Through a review of research projects and their results, this paper proposed six general criteria and 24 indices to be evaluated in six neighborhoods of Samen District in Mashhad. The result of paired comparisons revealed that among six main criteria, physical, structural, environmental, economic, social and service criteria had the greatest effect on weariness of urban neighborhoods respectively. In addition, with regard to the extent of weariness in neighborhoods under study, it was found that Eidgah, Payin Khiyaban, Tabarsi, Noghan, Bala Khiyaban and Chaharbagh had the highest level of weariness respectively.

Thus it can be concluded that the scale of weariness determined for neighborhoods under study based on the proposed criteria were different from the ones identified and approved by the Supreme Council for Planning and Architecture, which were based on the three physical parameters.

Such disparity can be explained based on the fact that this study also incorporated the effect of constructional, social, economic, environmental and service indices on neighborhoods under study. The above parameters are not extendable to all neighborhoods, districts and cities across the country and the weariness of a texture cannot be determined by a set of specific quantitative parameters. In the same manner, a similar method of intervention cannot be recommended for all

urban textures.

\section{References}

[1] Rahnama, M. [2009]. Planning for inner cities area (principles, theories, practices, and techniques). Mashhad: Ferdowsi University Press.

[2] Housing and Urban Development, Khorasan Razavi, Mashhad Urban Planning Studies Foundation [2015].Mashhad Municipality. [2014]. Statistical Yearbook of Mashhad.

[3] Mashhad Municipality Planning and Development.Habibi, M., \& Maghsoudi, M. [2007]. Urban restoration, definitions, theories, practices, charters and international resolutions related to urban practices and methods. Tehran: Tehran University Press.

[4] Habibi, M., \& Maghsoudi, M. [2007]. Urban restoration, definitions, theories, practices, charters and international resolutions related to urban practices and methods. Tehran: Tehran University Press.

[5] Andalib, A. [2006]. Renovation of worn-out textures, a new trend in the city of Tehran. Tehran: Tehran Revitalization Organization.

[6] Daviran, A., Meshkini, A., Kazamian, Gh. \&Aliabad, Z. [2011]. Analysis of intervention in improving worn-out and dysfunctional urban textures using an integrative approach (Case study: Zainabiyya neighborhood in Zanjan). Research and Urban Planning, 2 (7), 71-90.

[7] Azizi, Sh. [2010]. Developing criteria of identification of worn-out urban areas (case study: Shiraz. (Master thesis). Art University of Isfahan.

[8] Ahadnejad Roshti, M., Molaei Ghelichi, M., Javadzadeh Moghadam, H., \& Afshar Hatami, A. [2012]. Analysis of the spatial distribution pattern and its proper physical organization using GIS (Case astudy: District 8 of Tabriz). Research and Urban Planning, 3 (8), 1-18.

[9] Habibi, K., Pourahmad, A., \& Meshkini, A. [2007]. Betterment and renovation of worn-out urban textures. Tehran: Entekahb.

[10] Lotfi, S., Malekshahi, Gh. \& Mahdavi, M. [2010]. Strategic planning for the betterment of worn-out urban textures (Case study: city of Babol). $\mathrm{Hu}$ man Geography, 3 (1), 193-206.

[11] Falamaki, M. [2007]. Revitalization of monuments and historic towns. Tehran University

[12] Mahdizadeh, J. [2001]. An overview of city center restoration in the city of Tehran. Haft Shahr, 2 (3), 59-69.

[13] Abbasi, H., \& Razavi, R. [2006]. Designing an economic conceptual model for the rehabilitation and reconstruction of old textures. Proceedings to the Second Seminar on Construction in Capital. Faculty of Civil Engineering, Department of Engineering, Tehran University.

[14] Shamaei, A., \& Pourahmad, A. [2005]. Urban betterment and renovation from the standpoint of geography. Tehran: Tehran University Press.

[15] Jabari, H., \& Hassanzadeh, D. [2008]. Intervention in worn-out urban fabrics and future challenges (a critique of dominant approaches to intervention in worn-out urban areas). First Conference on betterment and renovation of worn-out urban textures. Iranian Construction and Development Company. Mashhad.

[16] Saaty, T. L., Peniwati, K., \& Shang, J. S. [2007]. The analytic hierarchy process and human resource allocation: Half the story. Mathematical and Computer Modelling, 46(7), 1041-1053. 